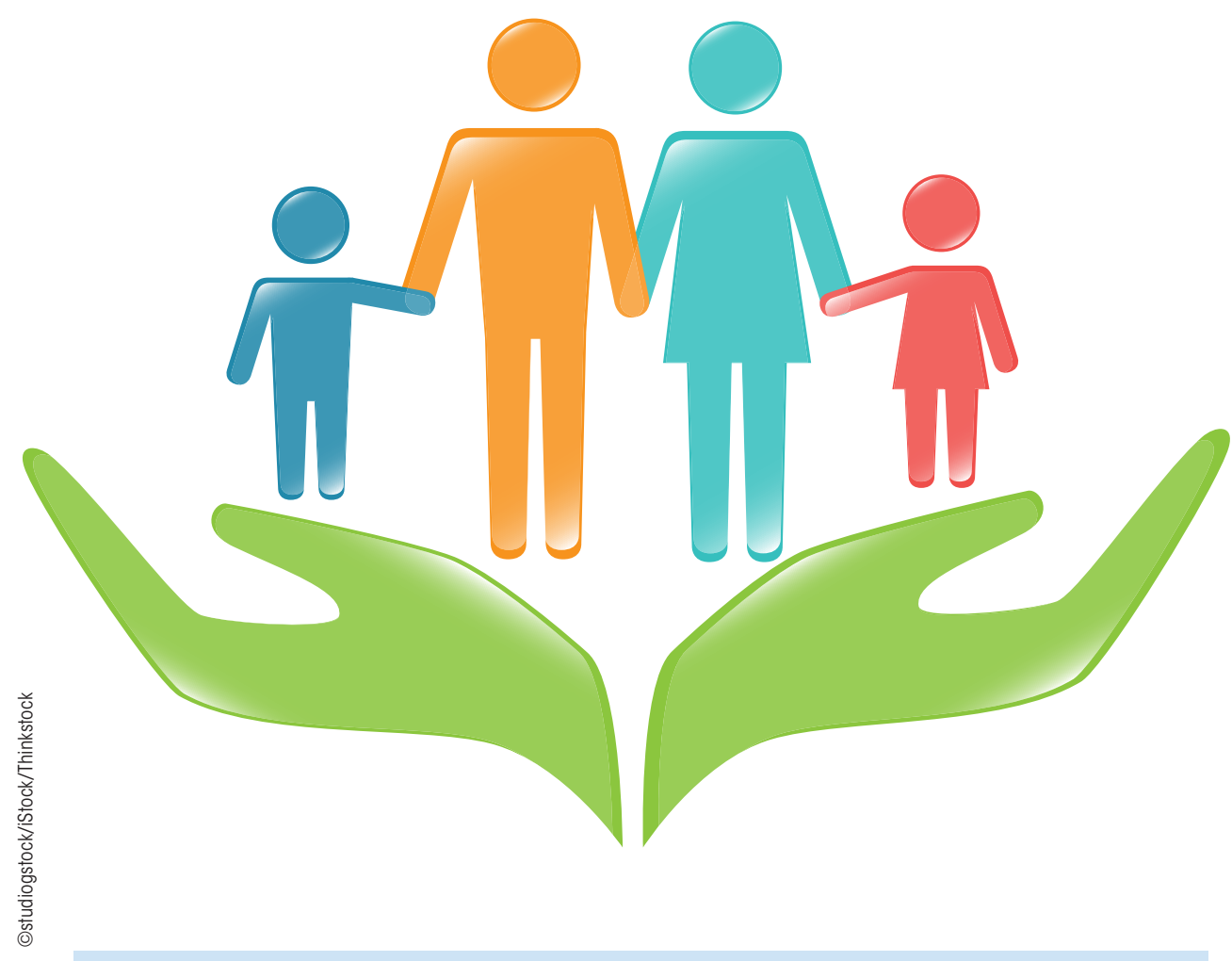

\title{
DENTAL HYGIENISTS AND THERAPISTS CAN HELP EXCEED PROFESSIONAL CONFIDENCE IN NHS DENTISTRY
}

A recent survey of dental professionals has found that confidence in future NHS dentistry plans is worryingly low with almost half of respondents having major concerns regarding treatment and prevention balance. ${ }^{1}$

The survey, which considered the opinions of 80 dental professionals, provided interesting insight into the thoughts and feelings of the profession in regards to NHS dentistry practice changes and tracked their levels of confidence.

Concerns were also raised about remuneration under new targets, career prospects and the ability to work within frameworks. But most of those surveyed remained confident that patients would continue to be happy at the service they received.

The British Society of Dental Hygiene \& Therapy (BSDHT) believes that these perceptions can be altered through correct utilisation of the entire dental team and that as a whole they can exceed all expectations.

Michaela ONeill, President of the BSDHT said: 'It is worrying that almost half of those surveyed felt that through
NHS dentistry they will be unable to strike a balance between treatment and prevention, especially when the key role of dental hygienists and therapists is that of providing preventative measures to stop further treatment down the line.

'By referring patients to dental hygienists and the dually qualified for preventative treatment at an early stage then other members of the dental team are freed to work towards other aspects within the framework and providing effective services for patients.

'The profession is striving to do the best for patients, sometimes under seemingly difficult conditions, and to do that effective preventative treatments must be delivered; this is where dental hygienists and therapists evidently can play an integral role.

'Close working relationships within the whole dental team and correct utilisation will enable the whole dentistry profession to exceed expectations when it comes to NHS dentistry.'

\footnotetext{
1. Practice Plan, NHS Confidence Monitor - https://www.practiceplan.co.uk/
}

CALL FOR DENTISTS TO INCREASE THEIR FOCUS ON TOOTH EROSION

The European

Federation of

Conservative

Dentistry

(EFCD) has

called for the

dental community

to increase its focus

on erosive tooth wear

and declared it a challenge requiring

co-operation with other healthcare

professionals, according to a recently published consensus report.

The Federation further concluded that effective management includes screening for early signs of tooth erosion and evaluating all aetiological factors, including eating and drinking habits, nutritional supplements, reflux, vomiting and medications.

Speaking about this consensus, Professor Andrew Eder, a Specialist in Restorative Dentistry and Prosthodontics, and Clinical Director of the London Tooth Wear Centre, commented: 'With people living longer, we need to work with our patients now to ensure their oral health does not let them down and one area that urgently needs our attention is that of erosive tooth wear.

'The Adult Dental Health Survey teaches us that more than threequarters of dentate adults show some tooth wear in their anterior teeth, while the increase in moderate tooth wear in 16 to 34 year olds is of clinical relevance as it is suggestive of rapid tooth wear.'

\section{Attending dental shoucase?}

To be in with a chance of winning an Apple Watch ${ }^{\mathrm{TM}}$, visit our stand $\mathrm{G} 55$ to

find out more! 